\title{
12
}

\section{Intonation in Six Dialects of Bininj Gun-wok}

\author{
Judith Bishop and Janet Fletcher
}

\subsection{INTRODUCTION}

The intonational systems of most non-Indo-European languages have been poorly studied relative to those of languages such as English, Swedish, German, or Dutch, for example. Yet it is particularly significant to examine the intonational systems of typologically diverse languages in light of renewed interest in 'intonational universals' (e.g. Vaissière 1995). A handful of intonational studies of languages as varied as Bengali (Hayes and Lahiri 1991), Balinese (Hermann 1997), and Chickasaw (Gordon, this volume Ch. 11) have appeared in the last ten years. Coupled with this is the growing interest in documenting intonational variation within dialects of a language. The analyses of the Venlo dialect of Dutch (Gussenhoven and van der Vliet 1999) and research on Swedish dialects (Bruce et al. 1999; this volume) are a welcome development.

It is not surprising therefore that few indigenous Australian languages have significant intonational descriptions, with the exception of Dyirbal (King 1992, 1994) a language once spoken in Northern Queensland, for which there are no remaining speakers; Warlpiri (King 1999), spoken in Central Austrailia; and Wik-Mingkan (Sayers 1974), spoken on the Cape York Peninsula, Queensland. In this chapter we examine the intonational phonology of six closely related varieties of a Northern Australian language, Bininj Gun-wok, also known as Mayali. We then outline transcription conventions which are

This work was carried out with the assistance of: an Australian Research Counci' Large Grant to the second author, Associate Professor Nicholas Evans, Intonation, Prosody and Meaning in Australian Languages (1998-2000); and an Australian Postgraduate Research Award and Faculty of Arts Field, work Grant to the first author. We wish to express our gratitude to all our language consultants, to Nicholas Evans for comments on earlier drafts of the paper, and to Murray Garde for providing us with recordings froin Kuninjku. 
designed to transcribe significant prosodic events in this language and its various dialects. The dialects are Gun-djeihmi, Kundedjnjenghmi, Kune, Kunwiniku, Kuninjku, and Manyallaluk Mayali.

Our study is located within the autosegmental-metrical (AM) intonational framework developed by Bruce (1977), Pierrehumbert (1980), Beckman and Pierrehumbert (1986), and Ladd (1996). According to this framework, and others such as the 'British School' of intonation (e.g. Halliday 1967), intonation performs a basic delimitative function across languages. In other words, there are tones that appear to perform some kind of phrasal edgemarking function in spoken language. Languages such as English, Japanese, Swedish, and French display various kinds of right-boundary-marking tone, i.e., a fall or rise that defines the right edge of a phrase. These phrase edges aie often accompanied by other junctural phenomena, namely lengthening, pause, or sandhi-blocking (Beckman 1996). In addition, the left edge of a constituent may be marked by a sharp rise in pitch. In languages such as Balinese (Hermann 1997), Korean (Jun 1993), and French (Jun and Fougeron 1995; Vaissière 1995), left and right edge boundary tones are the main indicators of intonational constituency.

According to Beckman (1996), many languages also have some kind of tonal event that is linked to a syllable or mora and performs a prominenceenhancing function within the domain of an intonational phrase. In many intonational descriptions of languages with metrical stress systems, this tonal event is called a pitch accent. Studies of American English intonation (e.g. Pierrehumbert 1980) and Austraiian English intonation (Fletcher and Harrington 1996) posit a relatively rich inventory of pitch accents, e.g. $\mathrm{H}^{*}$ (high), $\mathrm{L}+\mathrm{H}^{*}$ (rising), $\mathrm{L}^{*}+\mathrm{H}$ ('scooped' rise), and $\mathrm{L}^{*}$ (low), which are phonologically associated with one or moie rhythmically prominent syllables in a word. Dyirbal, like English, appears to have a prominence-marking tonal event that can be linked with rinythmically prominent syllables in a word (King 1994). However, King found that pitch accents in Dyirbal narratives, which were the basis of her study, have essentialiy only one shape, $\mathrm{LH}^{+} \mathrm{L}$.

The language under investigation in this chapter, Bininj Gun-wok (henceforth BGW), is a polysynthetic, non-configurational language of the Gunwinyguan family, spoken in western Arnhem Land (see Evans 1997a, $1997 b$, 2003: sec. 2.5.2.2) and is genetically only distantly related to Dyirbal. Like the latter, however, it has conventionally been described as a stress language (Evans 1995; Fletcher and Evans 200o) with no lexical use of pitch. Its polysynthetic structure results in complex metrical stress rules (see Evans $(1995,2003)$ and Bishop (2001, 2003: ch. 3) for a more detailed treatment than can be given here). Pitch accents can anchor to more than one metrically 


\begin{tabular}{|c|c|c|c|c|c|c|c|c|c|c|c|c|c|}
\hline \multirow[t]{2}{*}{$-12 \cdot 11-10$} & \multirow[t]{2}{*}{$(-9)(-4$} & \multirow[t]{2}{*}{$(-7)$} & \multirow[t]{2}{*}{$(-6)$} & \multirow{2}{*}{\multicolumn{2}{|c|}{$(-5)$}} & \multirow[t]{2}{*}{$(-4)$} & \multirow[t]{2}{*}{$(-3)(-$} & $(-2)$ & \multirow[t]{2}{*}{$(-1)$} & \multicolumn{2}{|c|}{ Embedded Verb } & \multirow{2}{*}{ e $(+1) \neq 2$} & \multirow[t]{2}{*}{$(+3)$} \\
\hline & & & & & & & & & & $(E-4)(E$ & $\bar{E}-0)(\mathrm{E}+3)$ & & \\
\hline 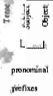 & 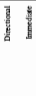 & $\frac{3}{2}$ & है & 2 & & $y$ & $\frac{\frac{2}{1}}{\frac{b}{8}}$ & $\frac{\frac{1}{5}}{\frac{3}{3}}$ & 8 & 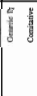 & 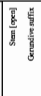 & $\frac{5}{5} \frac{1}{5}$ & है \\
\hline
\end{tabular}

Figure 12.1 Template structure of the verbal word in BGW.

strong syllable within the word: a single morphosyntactic word may carry two to three pitch accents.

Figure 12.1 illustrates the complexity of BGW morphosyntactic structure. The verbal word in BGW has the morphosyntactic template structure shown (adapted from Evans, forthcoming). The shaded 'slots' are obligatory, the parenthesized slots optional. Slots 6 and 7 are interchangeable in order. The relative linear order of the remaining slots is fixed, but it is never the case that all slots are filled at the one time. A Manyallaluk Mayali utterance, bani-weleng-bepbe-marne-yaw-bu-rr-iny, glossed as '3dualPast-then-separatelybenefactive-baby-hit-each.other-perfective', and translatable as 'Then the two of them fought each other over the baby', illustrates the filling of slots $(-12$ (zero prefix), -11$),(-7)$ (twice), $(-6),(-4),(0),(+1)$, and $(+2)$.

An example of double accentuation within a verbal morphosyntactic word (ngarri-yauh-maknan, 'we'll try looking at one more place') is given in Figure 12.2 below, and in a nominal word (gun-marlaworr-dorreng, "with a leaf'), in Figure 12.3.

Previous intonational analyses of two of the dialects examined here, Gun-djeihmi (Fletcher and Evans 2000) and Manyallaluk Mayali (Bishop 2003; Bishop, Fletcher, and Evans 1999) showed that the language falls into the typology of having both prominence-lending pitch movements and edgemarking pitch movements. In other words, the intonational typology of these dialects appears to be closer to Bengali (Hayes and Lahiri 1991) than to Korean. In the following sections we will briefly describe the main intonational contours observed for BGW and outline rules of tune-text association that give rise to these specific intonational patterns. We will then describe the transcription conventions that have been developed to capture significant prosodic events. 


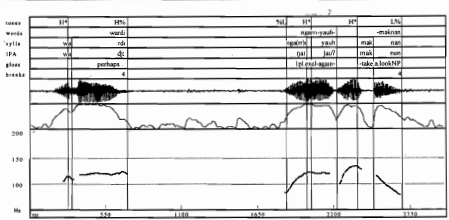

FIGURE 12.2 Hat pattern in Gun-djeihmi (across ngarri-yauh-maknan). Translation: 'We'll try looking at one more place.'

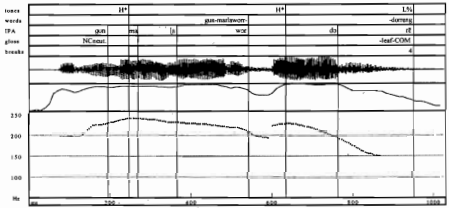

FIgUre 12.3 Hat pattern in Manyallaluk Mayali. Translation: With a leaf.

\subsection{OVERVIEW OF THE CORPUS}

All of the data presented in this chapter were recorded in the field by either the first author, Nicholas Evans, Murray Garde, or Peter Carroll as part of their fieldwork programmes on Northern Australian languages (Carroll 1995; Evans 2003; Garde 2003). The corpus consists of twelve narrative texts from 1.3 to to minutes in duration; one recording of an elicitation session and one of a 
conversation, mostly between two women, in Kuninjku; and two texts in Manyallaluk Mayali containing interrogative citation forms (twenty-six questions in total). The distribution of texts across the dialects is as follows: Gun-djeihmi (4), Kundedjnjenghmi (1), Manyallaluk Mayali (4), Kune (1), Kuninjku (5), and Kunwinjku (1). Of the Gun-djeihmi texts, three narratives were recorded from one male speaker and the remaining narrative text was produced by another male speaker. The Kundedjnjenghmi text was produced by one male speaker. Three of the Manyallaluk Mayali texts, including one set of citation forms, were spoken by one male speaker, with the remaining set of citation forms recorded from two female speakers. The Kune narrative was obtained from a female speaker, the Kunwinjku narrative from a male speaker, and the three Kuninjku narratives from a single male speaker. Intonation patterns in the latter texts were also found to occur in the text of a conversation between Kuninjku women. No gender-specific prosodic patterns are apparent in this corpus.

\subsection{THE MAIN INTONATIONAL CONTOURS OF BININJ GUN-WOK: TUNES ASSOCIATED WITH DECLARATIVE, INTERROGATIVE, AND IMPERATIVE CONSTRUCTIONS}

The main declarative tune consists of a 'pointed' or a 'flat' hat pattern, associated with an intonational phrase containing one or more pitch accented syllables, and a final fall to a low boundary. The hat pattern is found across all dialects. Figure 12.2 is an example from Gun-djeihmi and Figure 12.3 from Manyallaluk Mayali. General interpretations of this contour are similar to those associated with phrase-final falls in declarative utterances in other languages.

Another, less common, declarative tune consists of the hat pattern with a final rise at the right edge of the contour (Figures 12.4 and 12.5). The rise starts relatively low and ends at mid-level in a speaker's range. In all other respects, this contour resembles those illustrated in Figures 12.2 and 12.3. This contour is less frequent in the corpus than either of the other declarative tunes. In the Gun-djeihmi section of the corpus, for example, twenty-three out of a total of 221 intonational phrases are associated with this pattern.

The Fo range of the rise is generally not very large. Note, however, the extent of the rise in the Kune example (Figure 12.5), by contrast with the Manyallaluk Mayali example (Figure 12.4). Since the rise begins from a fairly low level in each of Figures 12.4 and 12.5, it does not appear to be the case that a distinct tune is involved. In the absence of evidence for the phonological 


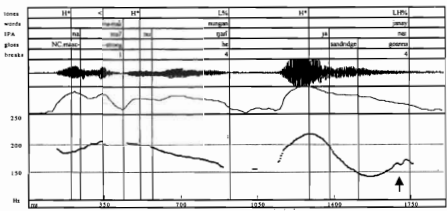

FIgure 12.4 Rising boundary in Manyallaluk Mayali

Translation: [But that (other) one], the strong one, sandridge goanna...

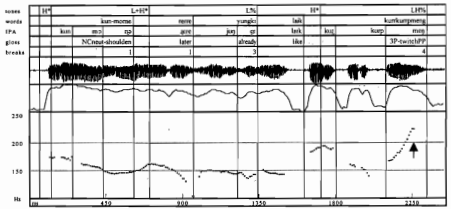

FIgURE 12.5 Rising boundary in Kune

Translation: [Later, his father already knew that something had happened to his son] betause his shoulder had been twitching. ${ }^{1}$

status of the higher rising contour, the high rise in the second example is presently treated as a phonetic raising of the high target of the rise.

A notable feature of the corpus is indeed the absence of any evidence for a phonological high rising tune (of the kind English ToBI annotates $\mathrm{H}-\mathrm{H} \%$ ). However, the corpus is limited in the genres it covers, and it is possible that expansion of the corpus to other genres (e.g. conversation) will require

${ }^{1}$ Translation from Erans, N. (2003), Bininj Gun-wok: A Pan-Dialectal Grammar of Mayali, Kune and Kunwinjku (Canberra: Pacific Linguistics). 
expansion of the tonal inventory established to date. The third tune used in declarative utterances is a high sustained contour reaching from the final accented syllable to the phrase edge. There are two variants of this tune. The first is illustrated in Figure $\mathbf{1 2 . 6}$ for Kundedjnjenghmi and the second is illustrated in Figure 12.7 for Kuninjku. In the first variant, the stretch of pitch between the final accent in the phrase (also the first, in this example) and the phrase edge is sustained at a mid-high pitch level. In the second variant, referred to as the 'stylized' high sustained contour, sustained mid to high pitch is combined with stylized lengthening of the phrase-final syllable

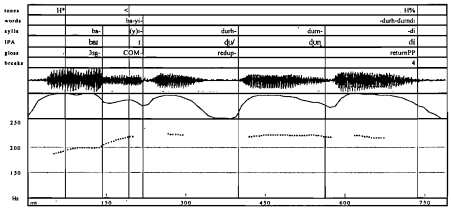

FIGURE 12.6 High sustained contour in Kundedjnjenghmi (non-stylized) Translation: $\mathrm{He}$ returited with it.

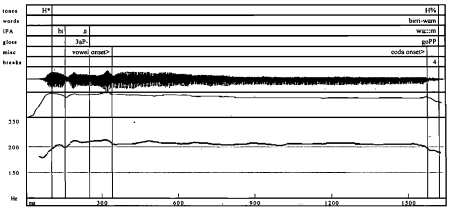

FIGURE 12.7 'Stylized' high sustained contour in Kuninjku (with vowel lengthening) Translation: They went along... 
nucleus. A coda consonant following the syllable nucleus is not stretched. Aithough this pattern is most frequently realized on the final vowel of verbal words, a nominal word following a verb may carry the vowel lengthening, indicating that the lengthening is a phrase-final edge effect rather than a kind of prosodic 'suffix' to the verbal word. The stylized sustained high contour type (Figure 12.7, above) is a strong feature of ali dialects of BGW. An analogous contour has also been observed impressionistically among several languages in Australia, such as Alawa (Sharpe 1972), Nunggubuyu (Heath 1984), Iwaija (Birch 1999), and Wik-Mungkan (Sayers 1974). The similarity of the contour across these languages is apparently semantic as well as formal. The meaning cited by Sharpe, for example, is among the meanings-of the contour in BGW: 'The pattern signifies continuous or prolonged action, motion, or state (according to the meaning of the verb)' (Sharpe 1972: 37).

Intriguingly, a somewhat similar phenomenon is recorded by Woodbury (1987) as occurring in two varieties of Central Alaskan Yupik (CAY), another polysynthetic language. The process of 'foot stretching' in CAY lengthens and raises the pitch of a foot-innal segment (nucleus or coda consonant). The process may affect only the initial (leftmost) foot in the intonation phrase, or it may also affect subsequent feet. Though the domain and intonational position of the effect differ from Bininj Gun-wok, the iconic content overlaps: as in BGW, 'the degree of stretching... is entirely up to the speaker' and as the formal effect increases in magnitude, 'the intensification which it signals also increases' (Woodbury 1987: 716). However, in CAY the device also typically 'underscores the surprise value' of the information, which it does not appear to do in BGW. In BGW, it more often serves as a means of 'setting the scene', or dramatizing a continuous, but backgrounded action (signalled by the stylized sustained high intonation), which is then punctuated by a momentary action or event.

Our observations of the intonation of interrogative constructions are based on a small set of predominantly Wh-questions. The few examples of polar questions in the corpus display a phrase-final fall (Figure 128). The tune associated with Wh-interrogatives is a high pitch accent peak on the phraseinitial Wh-question word or a demonstrative adjacent to it, foliowed by a phrase-final fall-rise-fall pattern (Figure 12.9; Bishop 1999). The rise-fall section of the pattern is aligned with either the final syllable or the penultimate syllable of the phrase (see Section 12.5.5 below for a discussion of the transcription of this tune as involving an accent plus boundary tone sequence rather than a bi- or tritonal boundary tone).

Imperative titterances show a very similar pattern of final fall-rise-fall. The small set of imperative utterances in the corpus are predominantly by the same speakers as the interrogatives (Figure 12.10). 


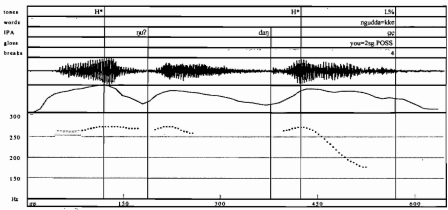

Figure 12.8 Polar question contour in Kuninjku Translation: 'It's YOURS?'

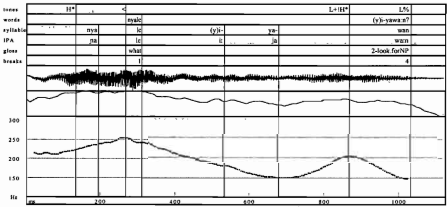

Figure 12.9 Wh-question contour in Manyallaluk Mayali

Translation: What are you looking for?

\subsection{PROSODIC STRUCTURE AND TUNE-TEXT ASSOCIATION IN BININJ GUN-WOK}

The segmental phonology of BGW provides few cues to prosodic domains of the kind described by Nespor and Vogel (1986) (see Section 12.5.7, 'Break

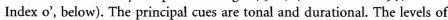
prosodic structure found to be relevant to a description of BGW intonation thus far are the foot, the phonological phrase, the intonational phrase, and the utterance. 


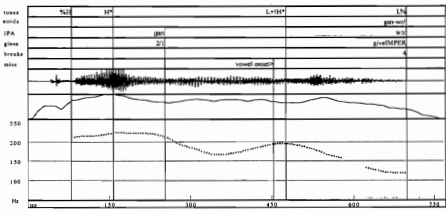

FIGURE 12.10 Imperative contour in Manyallaluk Mayali Translation: Give it to me!

The foot is trochaic and unbounded in all the BGW dialects (Bishop 2001, 2003: 22, 119). Metrical structure is assigned on the basis of morphological structure; morphemes are generally isomorphic with feet. The principal exceptions are a small set of morphemes which conjugate the root for tense, mood, and aspect, and prosodically cohere with the root to form a single foot. Evidence for the unboundedness of feet comes from tri- and quadrisyllabic monomorphemic nominal words, which bear stress on the initial syllable only, and, in unemphatic speech, do not carry a pitch accent on any other syllable:

$1 \quad{ }^{*}+* * *$

gorlomomo 'fresh water crocodile' (Manyallaluk Mayali dialect) not:

$\begin{array}{lll}1 & C^{*} C^{*} \\ 0 & * & * \\ & * & *\end{array}$

This stress pattern in monomorphemic words contrasts with the bimorphemic tri- and quadrisyllabic words. These regularly bear a pitch accent on each foot, which provides evidence of their bipedal metrical structure.

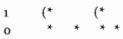

detjmak-duninj lit. hero-proper 'a real brave guy'

(Manyallaluk Mayali dialect) 


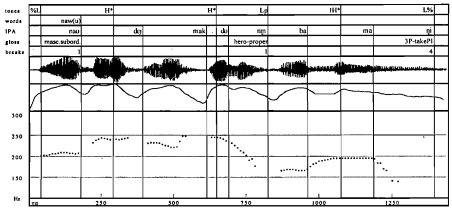

Figure 12.11 Double accented, bimorphemic nominal word in Manyallaluk Mayali Translation: That real brave guy would take it.

The morphological basis of metrical structure assignment often leads to adjacent stresses and even adjacent pitch accents. The prosodic system of BGW is unusual in showing a high tolerance for adjacent prosodic heads: there is no evidence of either stress- or accent-clash effects (Bishop 2001). Since the head of any foot in the morphological word provides a potential landing site for pitch accent, the morphological word in BGW may bear one, two, or exceptionally, three accents. We hear these as generally having similar perceptual prominence.

In the Kuninjku dialect, the phonological phrase is a level of phrasing that is tonally marked (with a low tone) at its right edge (see Figure 12.12, below). The phonological phrase is immediately dominated by the intonational phrase within the prosodic hierarchy postulated for BGW. Grammatically, the phonological phrase corresponds to the maximum level of lexical projection (VP, NP). As yet, no evidence has been gathered as to whether this level is also tonally marked in the other dialects, though, impressionistically, there is a similar phenomenon in the Kunwinjku and Manyallaluk Mayali dialects (see Figures 12.11, 12.14, and 12.19, in which the low phonological phrase edge tone is tentatively marked). ${ }^{2}$ In Kuninjku, relative prominence relations (downstep and upstep) hold between the final accents in adjacent phonological phrases. Detailed phonetic and phonological argumentation for

\footnotetext{
${ }^{2}$ An alternative analysis of the Low tone in these three examples is $\mathrm{L}+\mathrm{H}^{*}$. Further evidence (of the kind illustrated in Figure ${ }_{12.12}$ for Kuninjku, in which there is a clear low target marking the edge of the word bi-rrulubom) is needed to determine which analysis is appropriate.
} 


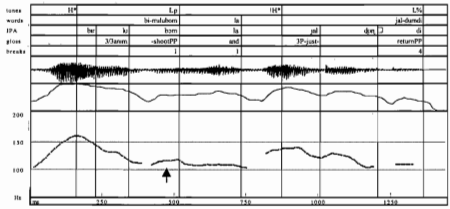

FIgure 12.12 Low Phonological Phrase boundary tone (Lp) in Kuninjku Translation: He shot/speared him and just came back.

the tonal marking of the phonological phrase level in Kuninjku is given in Bishop (2003: ch. 6). No final lengthening is associated with the phonological phrase level in that dialect.

The intonational phrase is defined on the basis of three characteristics: the relative prominence of pitch accents, boundary tone/s, and pitch reset. The intonational phrase is the domain within which the relative prominence relationships of downstep and upstep are constituted. Among the accents in the phrase, one accent tends to sound more prominent than the others: this is the 'head' or 'nucleus' of the intonational phrase. A single boundary tone or bitonal sequence associates with the right edge of the phrase, and is realized on the final syllable or two of the phrase. At the left edge of the phrase a new choice of pitch range is made, and downstep/upstep are blocked. The left edge may also be optionally marked by an initial boundary tone, $\% \mathrm{~L}$ or $\% \mathrm{H}$ (see Section 12.5.6). There is no clear evidence of phonetic boundaryassociated lengthening at the level of the intonational phrase.

A sequence of intonational phrases constitutes an utterance. There are two principal characteristics of the utterance: the potential for final lowering and substantial pause. A low intonational phrase boundary tone at the right edge of an utterance may be phonetically lowered relative to preceding low boundaries, producing the effect of final lowering. Not all intonation phrase-final falls show this extra low pitch. Also, the contours that display this feature do not always indicate that the speaker is 'done', and as yet we have found no consistent pragmatic or discourse function associated with this local lowering (Fletcher and Evans 2000). The end of the utterance is generally followed by 
more substantial pause than occurs utterance-medially. There are no additional boundary tores associated with the edge of the utterance. However, the final two syllables of the utterance generally undergo phonetic lengthening as a correlate of the boundary (Fletcher and Evans 2000; Bishop 2003: 355-9).

\subsection{TRANSCRIBING BININI GUN-WOK INTONATION}

\subsubsection{Overview of $B G W-T o B I$}

In this section we outline the BGW tonal irventory and transcription conventions adopted for the six dialects of Bininj Gun-wok. Our transcription system is closely based on the Tones and Break Indices system developed for Gereral American English (Pitrelli et al. 1994) and several other languages examined in this volume, for example Australian English (Fletcher and Harrington 1996), Korean (Beckman and Jun 1996), Japanese (Venditti 1997), and German (Grice et al. 1996). We will show how the same labelling conventions can be applied to all six dialects but will highlight how the few dialectal differences observed to date can be accounted for. A table summarising these conventions can be found in the Appendix.

Due to the morphological complexity of BGW we have added one further tier, a morphological gloss tier, to the usual four tiers of the classic ToBI model. All data are currently labelled using a modified version of 'Transcriber' developed for English ToBI. 'Transcriber' is an ESPS/Xwaves shell that has linked 'menu' files for each xlabel field. In some cases, these fields have been modified from the original English ToBI menus to account for Bininj Gun-wok-specific prosodic structure. For example, the tone menu has been modified to include specific diacritics for 'upstep' ( ${ }^{\wedge}$, as in '^ $\left.\mathrm{H}^{*}\right)$ and 'Final Lowering' ('Final_Lo'). The minimum signal' requirements for basic labelling include the acoustic waveform, fundamental frequency curve, and linked xlabel files. In some cases, spectrograms are also generated along with RMS amplitude traces to facilitate stressed syllable location and word level transcription. The five 'core' tiers currently included in the BGW-ToBI transcription are:

(I) a word tier

(2) a gloss tier

(3) a tone tier

(4) a break-index tier

(5) a miscelianeous tier. 


\subsubsection{Word tier}

The orthographic word tier in BGW-ToBI is similar to the orthographic tier in other ToBI systems. Words are transcribed using the conventional orthography developed by linguists in consultation with the community. Each word label is linked to the final segment of the word. Spectrograms are used where necessary to facilitate location of these right edges. Any hesitations or pauses are included in the miscellaneous tier.

Bininj Gun-wok is a highly polysynthetic language, so in many cases words are extremely long. As a general rule, hyphens have been used to indicate morphological division (refer to the Appendix for a key to the morphological glosses used in the illustrations to this paper). In the prosodic system of BGW, the morphosyntactic word generally corresponds to the phonological word. However we have observed certain instances of disjuncture between the morphological and phonological word in a closely related language, Dalabon, with certain prefixes appending to preceding phonological words. This will be the subject of further study.

\subsubsection{The morphological gloss tier}

A tier containing a morphological gloss is included in the conventions. This is essential because (1) labellers are not native speakers of the language; and (2) the study involves multiple dialects. The requirement of a gloss tier responds to the need for the researchers to understand the semantic structure of the utterances analysed. This understanding is of particular importance in the labelling of words and word groupings for which the cues to prosodic structure alone may be ambiguous.

The morphological gloss tier (illustrated in Figure 12.13 below) has the additional advantage of providing the basis for a cross-dialectal comparison of the relationship between prosodic and morphological structure. In all dialects, the rules for the construction of prosodic feet access the morpholegical structurc. However, constraints upon the construction of feet and the position of primary stress within the prosodic word vary between dialects in ways which are still in the process of being formulated (Bishop 2001).

\subsubsection{Tone tier}

There are two basic tone types included in the labelling conventions for the tonal tier-pitch accents and boundary tones. These conventions are 


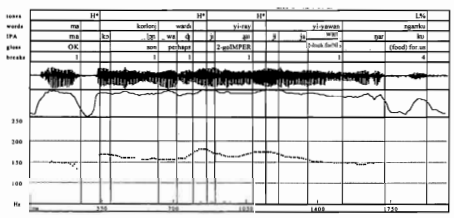

Figure 12.13 Word and morphological gloss tiers (Kune)

Translation: $O K$, my son, you go and look for something [for us to eat].

appropriate for all dialects in question, although we will discuss potential cross-dialectal realization differences at the end of this paper. Pitch accents are associated with stressed syllables and boundary tones with the right edge of phonological and intonational phrases. Rules for alignment of these tone types are outlined in Sections 12.5.5 and 12.5.6 below.

The inventory of tunes in BGW is relatively sparse compared with that of prototypical intonation languages such as Dutch and English. ${ }^{3}$ There are five pitch accent types, four of which are monotonal (high, delayed high, lowered (downstepped) high, and raised (upstepped) high) and one bitonal (lowrising). There is one type of phonological phrase boundary tone (low), and three types of intonation phrase boundary tone (low, high, and (low-) rising). The pitch accent types are discussed in Section 12.5.5, and the boundary tone types in 12.5.6.

\subsubsection{Types of pitch accents: (transcribed with *)}

Simple high $\left(\mathrm{H}^{*}\right)$ This is the main accent type in BGW. $\mathrm{H}^{*}$ is realized as a rise from the onset of the accented syllable to a peak within that syllable,

\footnotetext{
${ }^{3}$ It may be that BGW uses other aspects of the prosody to produce inferential meanings which are created in languages such as Dutch and English by the paradignatic choice of tune. These aspects might include, for example, phrasing and dephrasing, pitch range modifications, and possibly modifications of tune-text alignment (Bishop 2003).
} 


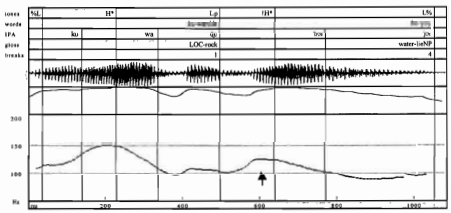

FIGURE 12.14 Downstepped high accent $\left(1 \mathrm{H}^{*}\right)$ in Kunwinjku Translation: Water lay in the cave.

usually aligned late in the syllable rhyme. The tone target is generally scaled within the mid-upper part of the speaker's Fo range.

Delayed high $h^{4}\left(\mathrm{H}^{*}<\right)$ The delayed high accent is realized as a rise from the onset of the accented syllable to a peak in the post-stress syllable (see Figures 12.4, 12.6, and 12.9 above). Following the ToBI conventions used for Korean and English, we label the highest Fo point with an additional diacritic ' $<$ ' to indicate 'late' peak (the angled bracket points back to the stressed syllable with which the peak is phonologically associated). The peak is never delayed beyond the post-stress syllable.

simple downstepped ${ }^{5}\left(\mathrm{H}^{*}\right)$ The tone target is lowered relative to a preceding high tone target within the intonation phrase. The alignment of the downstepped tone is similar to that of $\mathrm{H}^{*}$ simple accents. The preceding $\mathrm{H}$ target can be a simple $\mathrm{H}^{*}$ followed by a fall to a low phonological phrase boundary tone, an $\mathrm{L}+\mathrm{H}^{*}$ rising accent (described above) or an intonational phrase initial high boundary tone $(\% \mathrm{H}$; see above), which creates a 'high prehead' extending up to the first accent in the phrase.

Terraced downstepping contours of the kind noted in many other languages (Ladd 1996) are frequently found in all of the BGW dialects. Examples of this contour from Kunwinjku (Figure 12.14) and Kundedjnjenghmi (Figure 12.15) are given below. An upstepping sequence of accents occurs less frequently,

4 This accent type is referred to as the 'late peak' accent in Bishop (1999, 2000, 2003: 249ff).

${ }^{5}$ In Bishop (2003), $! \mathrm{H}^{*}$ and ${ }^{\wedge} \mathrm{H}^{*}$ are treated as modifications of underlying $\mathrm{H}^{*}$. Also, $\mathrm{L} \%$ is reanalysed as $L p-\%$, representing the association of the low phonological phrase boundary tone (Lp) to the intonation phrase boundary. However, these distinctions, and the reasons for them, cannot be developed in the present brief treatment of the inventory. 


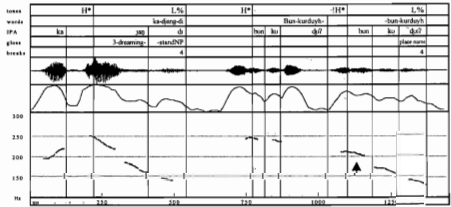

FIGURE 12.15 Downstepped high accent $\left(1 \mathrm{H}^{*}\right)$ in Kundedjnjenghmi Translation: There's a dreaming at Bunkurduyh-Bunkurduyh.

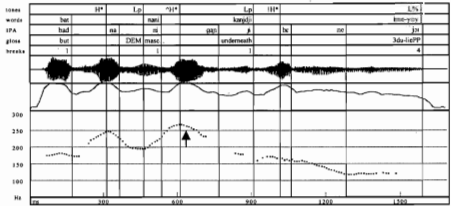

Figure 12.16 Upstepped high accent $\left({ }^{\wedge} \mathrm{H}^{*}\right)$ in Kuninjku Translation: But those two were lying underneath.

and may be followed by a downstepped accent within the intonation phrase (Figure 12.16).

Simple upstepped $\left({ }^{\wedge} \mathrm{H}^{*}\right)$ The tone target is raised relative to a preceding high accentual tone target within the intonation phrase. It is aligned in the same manner as $\mathrm{H}^{*}$ and $! \mathrm{H}^{*}$. So far, this accent has only been attested in the Kuninjku data (Figure 12.16).

Bitonal (low rising) $\left(\mathrm{L}+\mathrm{H}^{*}\right)$ This pitch accent consists of a high tone preceded by a rise from the low part of a speaker's pitch range. The rise is 
generally observed through the stressed syllable. In some cases the $\mathrm{L}$ is realized on a preceding syllable if the preceding material is highly sonorant.

It is necessary to distinguish this bitonal accent from a tonal sequence consisting of either an intonation phrase-initial L tone (transcribed \% L; see below), or a phonological phrase-final $\mathrm{L}$ tone (Lp), followed by $\mathrm{H}^{*}$. An $\% \mathrm{~L}$ $\mathrm{H}^{*}$ sequence is particularly common in the Gun-djeihmi dialect. There are two ways in which $\mathrm{L}+\mathrm{H}^{*}$ accents can be distinguished from such a sequence. There is usually tight temporal coupling between the low and high tone in the case of the bitonal accent. In the case of the $\% \mathrm{~L} \mathrm{H}^{*}$ sequence, the $\mathrm{L}$ is clearly anchored at the left phrase edge and can occur at some distance from the first $\mathrm{H}^{*}$ accent.

$\mathrm{L}+\mathrm{H}^{*}$ is also only labelled where the preceding $\mathrm{L}$ tone could not be accounted for as a phonological phrase-final low tone. In this respect, it is significant that we have observed word-medial instances of $\mathrm{L}+\mathrm{H}^{*}$ accents, where we cannot account for the $\mathrm{L}$ tone as a boundary tone associated with a preceding phrase edge (Figures 12.9 and 12.10 ). The rise in $\mathrm{L}+\mathrm{H}^{*}$ tends to be somewhat sharp and the $\mathrm{H}$ target is generally realized in the upper part of a speaker's range. However, in a sequence of $\mathrm{L}+\mathrm{H}^{*}$ tones the second $\mathrm{H}^{*}$ may be downstepped, and is labelled $\mathrm{L}+! \mathrm{H}^{*}$ accordingly (this is the case in Figures 12.9 and 12.10 above).

$\mathrm{L}+\mathrm{H}^{*}$ is a less frequent accent type in BGW. It may be dialect-specific in its distribution, as it does not occur in the data from the Kuninjku dialect analysed to date. In Gun-djeihmi narratives, the accent is usually employed to signal emphasis or narrow focus (Fletcher and Evans 1998). Similarly, in Kune and Manyallaluk Mayali, it sounds a more emphatic accent than a simple $\mathrm{H}^{*}$ pitch accent.

A particular use of the $\mathrm{L}+\mathrm{H}^{*}$ tone in Manyallaluk Mayali is in Wh-questions and imperative utterances (Figures 12.9 and 12.10). The phrase-final fall-risefall pattern which is associated with these utterances was originally analysed as $\mathrm{L}^{*} \mathrm{HL} \%$, with the $\mathrm{HL} \%$ sequences being realized as a rise-fall in the absence of a phonological upstep rule in the language. However, re-analysis of the alignment of the first $\mathrm{L}$ tone and the relatively strong auditory prominence of the $\mathrm{H}$ in the $\mathrm{HL}$ sequence indicates an analysis of $\mathrm{L}+(!) \mathrm{H}^{*} \mathrm{~L} \%$ is a more appropriate description of the tone pattern and its prosodic structure.

\subsubsection{Types of boundary tone}

One level of boundary tone is presently distinguished for all dialects: the intonational phrase level. A detailed analysis of Kuninjku (Bishop 2003: ch. 6) 
has also provided evidence for a tonally marked phonological phrase level in that dialect.

Phrasal tones are labelled at the end of each intonational phrase. The tone labels are generally aligned with the right edge of the last word in the phrase, as labelled on the orthographic tier. A feature of the boundary tone labels in BGW is that there is no phonological upstep rule for boundary configurations, in contrast with American and Standard Southern British English, or German (Grice et al. Ch. 13 this volume). That is, there is no evidence for an $\mathrm{H}-\mathrm{H} \%$ boundary tone sequence, denoting a high-rising tone, but only $\mathrm{H} \%$, used in BGW-ToBI to denote a level high tone, and LH\%, used to denote a low-rising tone. The balance between the most frequent boundary tone types, $\mathrm{L} \%$ and $\mathrm{H} \%$, varies considerably across texts. Although $\mathrm{L} \%$ tones generally predominate, the percentage of $\mathrm{L} \%$ boundary tones across all texts varied from 42 per cent to 93 per cent. $\mathrm{H} \%$ tones constituted between 7 per cent to 58 per cent of all boundary tones, while $\mathrm{LH} \%$ tones were rare, at between o per cent and 3 per cent of boundary tones.

Low phonological phrase boundary tone (Lp) The phonological phrase boundary tone is realized as a fall from the final high pitch accent in the phonological phrase to a low target aligned with the penultimate or final syllable of the phrase (see Figures 12.12, 12.14, 12.16). The phonological phrase is frequently isomorphic with a single morphosyntactic nominal or verbal word, but occasionally extends to two words (Bishop 2003: ch. 7).

Low intonational phrase boundary tone ( $\mathrm{L} \%$ ) This event is generally realized as a fall from the last pitch accent of a phrase reaching a low target near the baseline of a speaker's pitch range. The low target aligns with the penultimate or final syllable of the phrase (see Figures 12.5, 12.12, 12.15, 12.16). It is sometimes problematic to locate this tone clearly on the Fo curve if the speaker is elderly, as there is often a high level of creak which accompanies low boundary tones. The L\% tone may be additionally lowered in utterancefinal position by the final lowering modification (see Section 12.5.7, 'Break Index $4^{\prime}$ ), conveying a stronger sense of finality than the unmodified L\%.

High intonational phrase boundary tone $(\mathrm{H} \%)$ This is realized as a sustained high pitch or a slight rise from the last $\mathrm{H}^{*}$ accent in a phrase. (Refer to Figures 12.6 and 12.7 above.) There is evidently no rule of upstep: in a sequence of $\mathrm{H}^{*} \mathrm{H} \%$, the $\mathrm{H} \%$ is not necessarily realized higher in the speaker's pitch range than the preceding accent. This is similar to $\mathrm{H} \%$ boundary tones in Glasgow English ToBI (Mayo 1996), which also undergo no upstep. $\mathrm{H} \%$ is a common boundary configuration in narratives for all dialects. It is principally found utterance-medially, in descriptions of sequential actions, and in 
the initial phrase of a disiunction; the final boundary tone in such sequences is $\mathrm{L} \%$.

Low-rising intonational phrase boundary tone (LH\%) This boundary configuration phonetically resembles the 'continuation rise' of the English ToBI system. It generally involves a rise from the lower part of a speaker's range to a mid-level range, with both the low and the high target aligned with the final syllable of the phrase (refer to Figures 12,4 and 12.5). The range of meanings of $\mathrm{LH} \%$ in $\mathrm{BGW}$ is unclear, as there are few examples in the corpus. However, one use of $\mathrm{LH} \%$ would seem to be to solicit the hearer's attention to a new or newly re-introduced referent, as in the phrase but nawu... (L\%) na-mak nungan janay ( $\mathrm{LH} \%$ ) '[but that (other) one] ... the strong one, sandridge goanna...'.

Initial high boundary tone $(\% \mathrm{H})$ This represents a clear target in the high part of the speaker's pitch range which is not necessarily associated with a phonologically stressed syllable. $\% \mathrm{H}$ extends a level high plateau across any speech material preceding the first pitch accented syllable in the phrase (see Figure 12.17: the tone ending the preceding intonational phrase in this example is L\%). This tone, and the initial low initial boundary tone described below, are similar to the 'pre-head' of the British School of intonation. $\% \mathrm{H}$ is observed in all dialects.

Initial low boundary tone $(\% \mathrm{~L})$ This represents a target at the onset of an intonational phrase that is distinctly low in the speaker's range (as opposed to a default, mid-level onset), and does not align closely with a following high

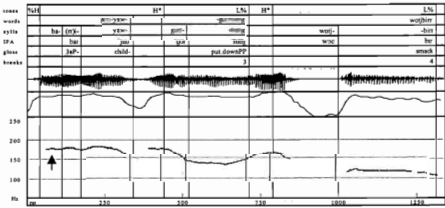

FIGURE 12.17 High Initial IntonationaI Phrase boundary tone $(\% \mathrm{H})$ in Manyallaluk Mayali

Translation: They put the crild down, smacked it. 


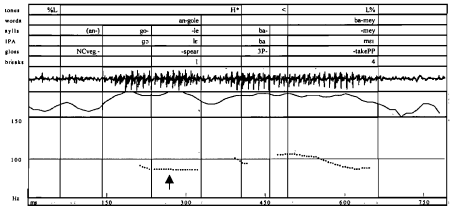

FIgURE 12.18 Low Initial Intonational Phrase boundary tone $(\% \mathrm{~L})$ in Gun-djeihmi Translation: $\mathrm{He}$ took a spear.

pitch accent, as the Low target does in the bitonal accent $\left(\mathrm{L}+(!) \mathrm{H}^{*}\right)$ (see Figures 12.9 and 12.10). When the first word in the phrase is unaccented, $\% \mathrm{~L}$ produces a low 'pre-head', a stretch of speech (in Figure 12.18, the word (an)-gole), with which a 'floating' Low tone target is associated. It is principally required for the description of tunes in Gun-djeihmi.

\subsubsection{Break indices}

The system of break indices enables the labelling of perceived degrees of prosodic juncture. Some levels of prosodic juncture are not tonally marked, and therefore not captured in the tonal tier, but may nonetheless be of relevance to the discourse and grammatical structures of languages. The break indices system may also be used to index the additional prosodic correlates of boundaries which are tonally marked, such as pause.

Four break index labels are adopted in the present analysis of Bininj Gun-wok: $0,1,3$, and 4 . The content of these labels is outlined below.

The break index labels for BGW map directly to two of the levels of the hierarchy of prosodic structure described in Section 12.4 above (the intonational phrase, BI 3 and the utterance, BI 4 ) and distinguish another (the phonological word and phonological phrase have the same level of perceived juncture, BI 1).

Break Index o: Break Index o is used where segments at a morphosyntactic word boundary are phonetically elided, and/or the position of a word 
boundary is reanalysed in fast speech. That is, the 'underlying' prosodic level of Break Index o is the level usually indicated by Break Index 1 (see below). It does not mark a separate level in the prosodic structure of BGW. In our corpus, Break Index o does not occur more frequently at some kinds of syntactic juncture than at others; nor are there systematic segmental phonological processes, such as liaison or epenthesis, with which the break index is associated. Therefore, for our purposes, Break Index o is considered to have the status of a phonetic label in a narrow transcription. In an utterance labelled ' ma o wurd 1', for example, a glottal stop at the end of the ' $m a$ ' is elided and the word boundary erased. A less transparent example is ' gun-dulk o yi-rratj(je) 1' (/gundułk \#\# jirarc/, pronounced [gundut \#\# kiraIc], in which there is both elision of the initial glide / $\mathrm{j} /$ and reanalysis of the word juncture. In the example illustrated in Figure 12.19 below, ' $n g a l(i)$ o ( $n g$ )albu', the final vowel / $\mathrm{L}$ / in the first word and the velar nasal onset of the second are elided.

Break Index o should only be used where it is not possible to discern the original word boundary. In all other cases, 1 or a higher level is preferable. Thus, the frequency of occurrence of Break Index o in our corpus, even in fast speech, is relatively low.

Break Index 1: Break Index 1 is the default, marking the minimal degree of juncture between a pair of morphosyntactic words in phrase-medial position. There is a distinct perception of the final and initial segments of the words, usually in the absence of physical pause. Examples of Break Index 1 are in Figures 12.19 and 12.20 .

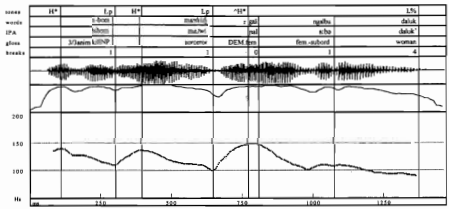

Figure 12.19 Break Indices 0,1 , and 4 in Kunwinjku

Translation: The clever man killed her, that woman. 


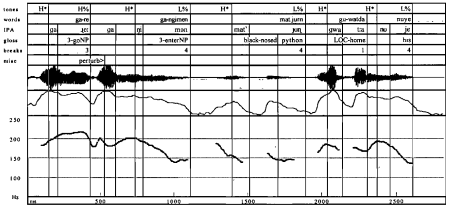

FIgURE 12.20 Break indices 1, 3, and 4 in Manyallaluk Mayali

Translation: The black-nosed python goes along, (then) into his hole.

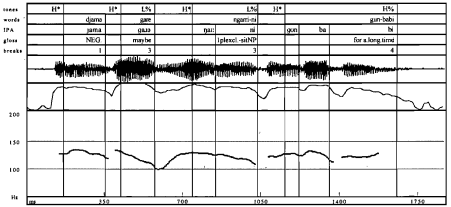

Figure 12.21 Break Indices 1, 3, and 4 in Gun-djeihmi

Translation: Maybe we won't stay here long.

Break Index 3: Break Index 3 is generally labelled at the right edge of an utterance-non-final intonational phrase (see Figures 12.20 and 12.21). There is at least one strong prominence per phrase, and a boundary tone realized at the right edge of the phrase. At the level of Break Indices 3 and 4 , the cues to juncture are a combination of a 'cumulative' cue occurring within the prosodic unit (the relative tonal prominence of the head) and 'demarcative' cues occurring at its edge (pause, lengthening, and boundary tone) (cf. Swerts et al, 1994). Clear pitch reset in the following phrase is a strong, though not 
a consistent, cue. Phrase-final lengthening (or 'virtual pause') is not a systematic cue to Break Index 3 . Impressionistically, Break Index 3 is also not associated with long pause; any pause tends to be no greater than 100 milliseconds following this juncture. Since substantial pausing tends to coincide with the percept of finality, Break Index 4 has been reserved for contours displaying one or both of these cues.

Break Index 4: Break Index 4 is used to mark an utterance-final intonational phrase juncture (see Figures 12.19, 12.20, and 12.21 above). This juncture resembles a Break Index 3 juncture tonally and with regard to its prominence features, but has one or more additional features: substantial pause, a sense of finality (associated with final lowering), or stylization (refer to Section 12.3).

Each of these features alone is sufficient to warrant labelling as Brcak Index 4. Finality is judged on the basis of whether, were the utterance to be synthetically cut off at the boundary, a listener would judge the speaker to have finished what they had to say (cf. Swerts et al. 1994). Though long pause is one correlate of Break Index 4 , and a sense of finality another, it is not necessarily the case that long pause is a cue to finality in Mayali. A-doctoral study of the rhetorical structure of Kunwinjku narratives by Carroll, for example, finds that '[p]ause units are grouped into tone units with the final pause unit having a falling intonation pattern' (Carroll 1995: 118). Carroll defines 'pause units' by the presence of a pause lasting at least 200 milliseconds, and 'tone units' by the fall to the baseline, which causes the percept of finality. It is clear that substantial pause is not associared uniquely with finality, but is used, at least in narrative, as a rhetorical and structural device (Carroll 1995). The extent to which pause is correlated with the level of the utterance (Break Index 4) may differ across languages and genres.

\subsubsection{Miscellaneous tier}

The miscellaneous tier is primarily used to note a variety of disruptions to the speech signal or the pitch trace, such as creak or phrase-final devoicing at low pitch; pitch doubling and halving, and microprosodic perturbations of the trace; disfluencies, hesitations and interruptions or turn-taking by another speaker (who may be identified in the miscellaneous tier for the purpose of discourse study); laughter; and various noises (children, dogs). It may also be used to mark silences (<sil sil $>$ ) for the purpose of studying the use of pause, and, where relevant, to indicate a stress or accent that is unusually positioned within the word (e.g. 'final syllable accented'). 


\subsubsection{Optional customized tiers: the syllable tier}

The syllable tier may serve as an important aid for research on languages in which the morphological word is regularly polysyllabic. Together with the morphological gloss tier, a syllable tier enables the determination of which morphemes are susceptible to elision, or fusion with neighbouring morphemes, and under what prosodic conditions. The syllable tier was also found to be useful for the study of tonal alignment in BGW (cf. Bishop et al. 1999).

\subsubsection{Additional features of our labelling system}

There are two additional features associated with the labeling of pitch range.

HiFo: we have retained the same convention as English ToBI to mark the highest Fo value associated with a high accent in each intonational phrase. Only Fo targets associated with $\mathrm{H}^{*}$ accents are labelled. Segmental perturbations are taken into account when labelling HiFo.

Final_Lo: we have added this optional label to our tone menu to represent the 'extra' lowering of pitch that can occur at the end of an utterance-final intonational phrase. With elderly speakers, there is also a high level of creak accompanying these 'extra low' boundary tones. This label is particularly relevant for our work on intonation and discourse (cf. Fletcher and Evans 2000).

\subsection{CROSS-DIALECT AND CROSS-LANGUAGE DIFFERENCES}

Differences among the dialects for which data has been analysed do not appear to be substantial. The few differences we have posited are predominantly of the 'systemic' type, that is: 'differences in the inventory of phonologically distinct tune types, irrespective of semantic differences' (Ladd 1996: 119, following Wells (1982)). For example, the initial low intonational boundary tone $\% \mathrm{~L}$ frequently occurs in Gun-djeihmi, but does not appear to feature in the inventory of Kuninjku. On the other hand, upstepping accents within an intonational phrase are only recorded for Kuniniku. These may be simply gaps in the data; further data in each dialect, from a larger number of speakers and a more extensive range of genres is required to address this question.

We would like to conclude with some general comments on the prosodic patterns observed in our Bininj Gun-wok corpus. Speakers of the Bininj Gun-wok dialects examined here use intonational parameters such as pitch 
range reset, local downstep, and final lowering extensively to provide certain kinds of discourse effects: initiating a new topic, introducing new participants, closing an old topic, and so forth. Our preliminary observations suggest that in this respect, BGW does not differ from other intonational languages.

Given the polysynthetic nature of this language, we speculate that there may be fewer instances of word-level prosodic juncture (Break Index 1) in Bininj Gun-wok compared to more morphologically isolating languages. Many morphosyntactic words in BGW constitute BI 3 or BI 4 units. These words range from one syllable to upwards of seven syllables in length. A survey of accent frequency across Manyallaluk Mayali, Kune, Kunwinjku, and Gun-djeihmi texts showed a ratio of pitch accents to words ranging between 0.71 (a Manyallaluk Mayali text) to 0.92 (Kunwinjku). This is a high rate of accentuation, which may reflect (a) the absence of deaccentuation as a pragmatic device in Bininj Gun-wok and (b) the paucity of unaccented 'function' or non-'content' words in this language. The ratio of accents to words is also raised by the presence of double accentuation in certain kinds of morphological words, such as complex verbal constructions.

A survey of boundary tone frequenc across Manyallaluk Mayali, Kune, and Kunwinjku texts showed a ratio of 1.5 to 2.1 words per boundary tone (Break Index 3 or 4 ). The high frequency of boundary tones reflects the fact that Inuch information in the clause is incorporated into the verb in BGW (see Figure 12.1), reducing the use of free nominal and adverbial words to instances where further specification of information (that is otherwise simply indexed on the verb) is needed. There is therefore a close mapping between a single clause (minimally, a verb with a pronominal prefix and inflectional suffixes) and a single intonational break ( $\mathrm{BI} 3$ or 4 ). An examination of two Manyallaluk Mayali narratives showed 91 per cent of clauses in one narrative (thirty-one out of thirty-four clauses) and 86 per cent of clauses in another (sixty-nine out of eighty clauses) map onto single intonational phrases. It would be interesting to compare our findings to other polysynthetic languages to see if similar trends are evident.

\section{APPENDIX}

Key to morphological glosses used in the text

Verbal prefixes

$1,2,3$

First, second, third person

sg., pl., a, du

Singular, plural, augmented $(3+)$, dual 


$\begin{array}{ll}\text { anim. } & \text { Higher animate } \\ \mathrm{p} & \text { Past } \\ 3 / 3 & \text { Third person subject affecting third person object } \\ \text { excl./incl. } & \text { Exclusive/inclusive } \\ \text { BENE. } & \text { Benefactive } \\ \text { COM. } & \text { Comitative } \\ \text { redup. } & \text { Reduplicant morpheme }\end{array}$

Verbal suffixes

NP Non-past

PI Past imperfective

PP Past perfective

IMPER. Imperative modality

Nominal prefixes

NCmasc./fem./veg./neut Noun class marker (masculine, feminine, vegetable, and neuter classes)

LOC. Locative prefix

Nominal suffixe:

LOC. Locative suffix

COM. Comitative suffix

POSS. Possessive suffix

Other

masc.subord./fem. subord. Subordinating conjunction - bu with masculine/feminine gender agreement

NEG. negative particle

DEM.masc./fem Demonstrative with masculine/feminine gender agreement

\section{Summary of BGW_ToBI labels}

$\mathrm{H}^{*} \quad$ Simple high accent: marked on a stressed syllable. Indicates an accent rising from the onset of the stressed syllable to an Fo peak on that syllable.

$\mathrm{H}^{*}<\quad$ Delayed high accent: marked on a stressed syllable. Indicates an accent rising from the onset of the stressed syllable to an Fo peak on the poststress syllable.

$\mathrm{IH}^{*} \quad$ Simple downstepped accent: marked on an Fo peak that is lowered relative to a preceding high accent peak.

${ }^{\wedge} \mathrm{H}^{*} \quad$ Simple upstepped accent: marked on an Fo peak that is raised relative to a preceding high accent peak.

$\mathrm{L}+\mathrm{H}^{*} \quad$ Bitoral (low rising) accent: marked on an Fo peak preceded by a rise from the lower part of the speaker's range. 
Lp Low phonological phrase boundary tone: marked at the right edge of a phonological phrase.

L\% Low intonational phrase boundary tone: marked at the right edge of an intonational phrase.

$\mathrm{H} \% \quad$ High intonational phrase boundary tone: marked at the right edge of an intonational phrase displaying sustained high pitch after a final Fo peak in the phrase.

LH\% Low-rising intonational phrase boundary tone: marked at the right edge of an intonational phrase.

$\% \mathrm{~L} \quad$ Initial low intonaiional phrase boundary tone: marked at the left edge of an intonational phrase. Indicates an onset at a distinctly low level.

$\% \mathrm{H} \quad$ Initial high intonaticnal phrase boundary tone: marked at the left edge of an intonational phrase. Indicates an onset at a distinctly high level, but not associated with a high Fo accent peak.

o

Break index: zero disjuncture: indicates it is not possible to discern a word boundary, typically in fast and casual speech.

Break index: weak disjuncture: typical of word- and phonological phrase-level boundaries.

3 Break index: medium disjuncture: typical of utterance-medial intonational phrase boundaries.

4 Break index: strong disjuncture: typical of utterance-final boundaries.

HiFo Highest Fo: marked at the highest Fo value associated with a high accent peak in each intonational phrase.

Final_Lo Final lowering: marked at the right edge of an utterance displaying 'extra' lowering of pitch, signalling finality.

Note: the IPA font used in the Figures and in the body of the text is SIL-Doulos Regular (12).

\section{REFERENCES}

Beckman, M. E. (1996), 'The Parsing of Prosody', Language and Cognitive Processes, 11: $17-67$.

—, and JUN, S.-A. (1996), 'K-ToBI (Korean ToBI) Labeling Conventions, Version 2', ms, Ohio State University and University of California, Los Angeles.

- and Pierrehumbert, J. (1986), 'Intonational Structure in Japanese and English', Phonology Yearbook, 3: 255-30\%.

BIRCH, B. (1999), 'Prominence Patterns in Iwaija', B.A. (Hons.) dissertation (University of Melbourne, Australia).

Bishop, J. (1999), 'The When, Where and How of the Intonational Structure of Wh-questions in Manyallaluk Mayali', Melbourne Papers in Linguistics, 18 (Department of Linguistics \& Applied Linguistics, University of Melbourne). 
Bishop, J. (2000), 'Prosodic Context and the Timing of Fo Peaks: Late Peak Alignment in Bininj Gun-wok', paper presented at the Australian Linguistics Society conference, Melbourne, Australia, $7-9$ July.

- (2001), "Metrical Structure, "Primary Stress" and Intonational Pitch Accent in Kuninjku', paper presented at the Australian Linguistics Society conference, Canberra, Australia, 27-30 Sept.

- (2003), 'Aspects of Intonation and Prosody in Bininj Gun-wok: Ar Autosegmental-Metrical Analysis', Ph.D. dissertation (University of Melbourne, Australia).

- Fletcher, J., and Evans, N. (1999), 'Tonal Alignment in Mayali', in Proceedings of the XIVth International Congress of Phonetic Sciences (San Francisco, CA), 2371-4.

Bruce, G. (1977), Swedish Word Accents in Sentence Perspective (Lund, Sweden: CWK Gleerup).

(this volume Ch. 15), 'Intorational prominence in Varieties of Swedish Revisited'.

- Elert, C., Englstrand, O., and Wretling, P. (1999), 'Phonetics and Phonology of the Swedish Dialects', in Proceedings of the XIVth International Congress of Phonetic Sciences (San Francisco, CA), 321-4.

Carroll, P. (1995), 'The Old People Told Us: Verbal Art in Western Arnhem Land', Ph.D. dissertation (University of Queensland).

Evans, N. (1995), 'Current Issues in the Phonology of Australian Languages', in J. Goldsmith (ed.), The Handbook of Phonological Theory (Cambridge, MA: Blackwells), 723-61.

- $(1997 a)$, 'Role or Cast? Noun Incorporation and Complex Predicates in Mayali', in A. Alsina, J. Bresnan, and P. Sells (eds.), Complex Predicates (Stanford: CSLI), $397-430$.

- $(1997 b)$, 'Head Classes and Agreement Classes in the Mayali Dialect Chain', in M. Harvey and N. Reid (eds.), Nominal Classification in Aboriginal Australia (Amsterdam: John Benjamins), 105-47.

- (2003), Bininj Gun-wok. A Pan-dialectal Grammar of Mayali, Kunwinjku and Kune (Canberra: Pacific Linguistics).

Fant, G., and Kruckenberg, A. (1993), 'Towards an Integrated View of Stress Correlates', Proceedings of the ESCA Workshop on Prosody (Lund: Lund University).

Fletcher, J., and Evans, N. (1998), 'Intonational Categories in Mayali', paper presented at Laboratory Phonology VI, York, 2-4 July.

$\longrightarrow-(2000)$, 'Intonational Downtrends in Mayali', Australian Journal of Linguistics, 20/1: 23-38.

- and Harrington, J. (1996), 'Accentual-Prominence-Enhancing Strategies in Australian English', in P. McCormack and A. Russell (eds.), in Proceedings of the VIth Australian International Conference on Speech Science and Speech Technology (Canberra: Australian Speech Science and Technology Association), 577-80. 
GARDE, M. (2003), 'Topics in Kuninjku Ethnography of Speaking', Ph.D. dissertation (University of Queensland).

Gordon, M. K. (this volume Ch. 11), 'Intonational Phonology of Chickasaw'.

Grice, M., Baumann, S., and Benzmüller, R. (this volume Ch. 3), 'German Intonation in Autosegmental-Metrical Phonology'.

- Reyelt, R, Benzmüller, R., Maher, J., and Batliner, A. (1996), 'Consistency in Transcription and Labelling of German Intonation with GTOBI', in Proceedings of the 4 th International Conference on Spoken Language Processing (ICSLP: Philadelphia), 1716-19.

Gussenhoven, C., and Vliet, P. VAN DER (1999), 'The Phonology of Tone and Intonation in the Dutch dialect of Venlo', Journal of Linguistics, 35: 199-235.

Halıidsy, M. A. K. (1967), Intonation and Grammar in British English (The Hague: Mouton).

HAYES, B., and LAHIR1, A. (1991), 'Bengali Intonational Phonology', Natural Language and Linguistic Theory, 9: 47-96.

Heath, J. (1984), Functional Grammar of Nunggubuyu (Canberra, Australia: Australian Institute of Aboriginal Studies).

Hermann, R. (1997), 'Syntactically-Governed Accentuation in Balinese', $O S U$ Working Papers in Linguistics, 50: 679-99.

jun, S.-A. (1993), 'The Phonetics and Phonology of Korean Prosody', Ph.D. dissertation (Ohio State University). [Published in 1996, New York: Garland.]

- and Fovgeron, C. (1995). The Accentual Phrase and the Prosodic Structure of French, in Proceedings of the thirteenth International Congress of Phonetic Sciences (Stockholm), 2: 722-5.

KING, H. (1992), 'Dyirbal Intonation', in J. Ingram and J. Pittam (eds.), Proceedings of the Fourth Australian International Conference on Speech Science and Speech Technology, 597-601.

- (1994), The Declarative Intonation of Dyirbal: An Acoustic Analysis, MA dissertation (Australian National University).

- (1999), 'High Onset Pitch Accents? The Case of Dyirbal and Warlpiri', in Proceedings of the XIVth International Congress of Phonetic Sciences (San Francisco, CA), 2403-6.

LADD, D. R. (1996), Intonational Phonology (Cambridge: Cambridge University Press).

Mayo, C. (1996), 'Prosodic Transcription of Glasgow English: An Evaluation Study of Gla-ToBI', M.Sc. dissertation (University of Edinburgh).

Nespor, M., and Vogel, I. (1986), Prosodic Phonology (Dordrecht: Foris).

Pierrehumnert, J. (1980), 'The Phonetics and Phonology of English Intonation', Ph.D. dissertation (Massachusetts Institute of Technology).

Pitrelli, J. F., Beckman. M., and Hirschberg, J. (1994), 'Evaluation of Prosodic Transcription Labeling Reliability in the ToBI Framework', Proceedings, 1994 International Conference on Spoken Language Processing, 1: 123-6. 
Price, P. J, Ostendorf, M., Shattuck-Hufnagel, S., and Fong, C. (1991), 'The Use of Prosody in Syntactic Disambiguation', Journal of the Acoustical Society of America, 90/6: 2956-70.

SAYERS, B. (1974), Interpenetration of Stress and Pitch in Wik-Mungkan Grammar and Phonology (Part 1) (Summer Institute of Linguistics).

Sharpe, M. (1972), Alawa Phonology and Grammar (Canberra: Australian Institute of Aboriginal Studies).

Swerts, M., Bouwhuls, D. G., and Collier, R. (1994), 'Melodic Cues to Perceived Finality of Utterances', Journal of the Acoustical Society of America, 96/4: 2064-75.

VAIsstère, J. (1995), 'Phonetic Explanations for Cross-Linguistic Prosodic Similarities', Phonetica, 52: 123-30.

VenditTI, J. (1997), 'Japanese ToBi Labelling Guidelines', Ohio State University Working Papers in Linguistics, 50: 127-62.

Woodbury, A. (1987), 'Meaningful Phonological Processes: A Consideration of Central Alaskan Yupik Eskimo Prosody', Language, 63/4: 689-740. 


\section{University Library}

\section{- M M I N E R VA A gateway to Melbourne's research publications}

Minerva Access is the Institutional Repository of The University of Melbourne

Author/s:

BISHOP, JB;FLETCHER, J

Title:

Intonation in Six Dialects of Bininj Gun-wok

Date:

2005

Citation:

BISHOP, J. B. \& FLETCHER, J. (2005). Intonation in Six Dialects of Bininj Gun-wok. JUN, S (Ed.). Prosodic Typology: The Phonology of Intonation and Phrasing, (1), 9780199249633, pp.331-361. Oxford University Press.

Persistent Link:

http://hdl.handle.net/11343/25941 